\title{
Why economic valuation does not value the environment: climate policy as collective endeavour
}

Article

Accepted Version

Bardsley, N., Ceddia, M. G., McCloy, R. and Pfuderer, S. (2021) Why economic valuation does not value the environment: climate policy as collective endeavour. Environmental Values. ISSN 1752-7015 doi: https://doi.org/10.3197/096327121X16081160834740 Available at https://centaur.reading.ac.uk/91985/

It is advisable to refer to the publisher's version if you intend to cite from the work. See Guidance on citing.

To link to this article DOI: http://dx.doi.org/10.3197/096327121X16081160834740

Publisher: White Horse Press

All outputs in CentAUR are protected by Intellectual Property Rights law, including copyright law. Copyright and IPR is retained by the creators or other copyright holders. Terms and conditions for use of this material are defined in the End User Agreement.

www.reading.ac.uk/centaur 
Central Archive at the University of Reading

Reading's research outputs online 


\title{
Why economic valuation does not value the environment: climate policy as collective endeavour
}

\begin{abstract}
Economics takes an individualistic approach to human behaviour. This is reflected in the use of "contingent valuation" surveys to conduct cost benefit analysis for economic policy evaluation. An individual's valuation of a policy is assumed to be unaffected by the burdens it places on others. We report a survey experiment to test this supposition in the context of climate change policy. Willingness to pay for climate change mitigation was higher when richer individuals were to bear higher costs than when, as is usual, no explicit information was provided about cost distribution. This result is inconsistent with the usual interpretation of contingent valuation data. It also suggests that the data may be biased indicators of policy acceptance. Additional survey questions suggest that a collective mode of reasoning is common.
\end{abstract}

Keywords: contingent valuation, climate change mitigation, public opinion, methodological individualism

\section{Introduction: Individualism, Contingent Valuation and Policy Acceptance ${ }^{1}$}

Modern economics is committed to methodological individualism, the doctrine that society is always to be understood in terms of the individuals that comprise it (Boland, 1982; Udehn, 2002). This leads to a distinctive emphasis on the individual in much applied economic research and policy analysis (Adieh, 2011). We examine one manifestation of this emphasis of particular importance to environmental policy discourse, namely economic cost benefit analysis (CBA). Using CBA, a policy is evaluated by estimating how much money its prospective outcomes are worth to each individual member of the relevant population. Individuals' valuations are summed yielding a total value to be compared to the costs of the policy. A positive evaluation is returned only if total benefits exceed total costs. In that case, the policy is potentially "Pareto improving" or "efficient", meaning that it would be possible for everyone to be better off under the policy.

In many contexts, for CBA to be applied, monetary values need to be assigned to the outcomes under evaluation, despite the fact that they do not have market prices. This is generally the case for environmental policies. There is no price on clean air, for example, such that people are used to thinking about whether or not to pay for more of it. For this reason, "contingent valuation" (CV) is often used, in which a survey respondent is asked about a hypothetical transaction to acquire the environmental benefit. Whilst a policy might require collective action to achieve a goal, then, the CV scenario used to evaluate it essentially depicts an individual survey respondent exchanging some of their own money for the benefit.

The individualism of CBA and the CV technique align with that of the broader economics discipline. Welfare economics, for example, aims to represent the welfare of society as a function of each individual's welfare (Sen, 1973). Further, the welfare of an individual is generally represented only as a function of her desired consumption outcomes, rather than outcomes for others. Interdependencies in preferences or welfare, whilst studied as interesting technical cases by economic

\footnotetext{
${ }^{1}$ Declaration of interests: none. The authors would like to acknowledge funding from the Leverhulme Trust, grant RPG-2014-404, and audiences at the University of Oslo, the Autonomous University of Barcelona and the University of Reading for valuable comments.
} 
theorists (for example, Pollack, 1976; Bergstrom 1989; Ley 1997), are generally not considered as central cases or investigated in routine applied work.

Welfare-relevant outcomes have been broadly conceptualised by environmental economists, to include desiderata such as the existence of polar bears or the integrity of the Arctic ice cap. But CV follows the general practice of excluding distributional matters from valuations, that is, how much different sections of society stand to gain or lose (Carson and Haneman, 2005 section 3, Bockstael and Freeman 2005, section 2). This is despite the fact that securing environmental outcomes would involve mass cooperation, and so a broad dispersion of costs. Such dispersion raises important equity and equality issues. These are particularly marked in the case of climate change policy, partly because of unequal distribution of consumption-based emissions across households (Brand and Boardman, 2008; Bardsley et al., 2017; Gough, 2017).

In so far as distributional concerns are recognised then, the working assumption is that they are separable from environmental valuation. This assumption contributes crucially to the analytical power of CBA, for the questions of whether a policy is socially desirable and how to implement it can then be considered separately. However, this separate treatment seems justifiable only if the working assumption is empirically correct. Investigation of this matter is the central focus of this paper. Proponents of "deliberative valuation" (see O'Neill and Spash, 2000, Spash 2008b, and Vargas et al. 2017 for recent critical discussion) have argued that evaluative attitudes relevant to policy are not simply preferences on a consumer choice model. Rather they are judgements about what is right, and so subject to ethical deliberation, such that environmental valuation ought not to strip out equity considerations. If so, one would expect stated WTP values to be sensitive to cost shares, and this result would provide additional impetus to use and refinement of alternative methods to inform policy.

A large literature exists on CV, including a set of significant controversies - see for example Oerlemans et al. (2016), Hausman (2012), World Bank (2012), Venkatachalam (2004), and Diamond and Hausman (1994). One concern is whether the elicited values represent pre-existing dispositions or are purely reactions to the survey instruments. Another is whether assigning monetary values to ecosystems is consistent with perceived ethical duties to protect them. Despite strong criticism, however, monetary valuation methods including $\mathrm{CV}$ are resurgent with the advent of the "ecosystem services" paradigm, (Spash and Aslaksen, 2015; Spash, 2008a). We believe new critical scrutiny is therefore timely. An important partial defence of $\mathrm{CV}$ is that the numbers collated may be meaningful even if one rejects the economic framework the technique is derived from. This may have been first articulated by Naess (1989), who rejects the economic interpretation of CV data as direct measures of the value of a policy on philosophical grounds, but also argues that $\mathrm{CV}$ is of value as opinion research. In the context of climate policy, CV data might be interpreted as information about policy acceptance. But such a position raises questions about the quality of the data, so interpreted. Sensitivity of WTP to cost shares could also bias CV under this broader interpretation.

The individualism of CV seems not to have been subject to close empirical scrutiny. We focus on climate change policy for this both because of its topicality in the wake of the Paris agreement, and because it impacts on the whole population, rendering the exclusion of distributional concerns particularly problematic. For a review of 27 studies estimating WTP for climate change mitigation, see Johnson and Nemet (2010). The review finds huge variation in participants' mean WTP, ranging from $\$ 22$ to $\$ 2623$ per household across studies (in 2008 dollars), partly reflecting diversity in policy scenarios, and so variation in the marginal changes to public good supplied. The studies generally employed CV, and did not inform respondents about distributional aspects of policies, other than an implicit "flat rate". A flat rate policy is one where everyone simply pays the same amount, and would 
cost poorer people more as a proportion of income. Cai et al. (2010) report that WTP for climate change mitigation is sensitive to the distribution of burdens between countries, and to shares of different policy instruments within a country. They interpret this as showing sensitivity of WTP to distributional concerns between rich and poor, but other factors such as the perceived effectiveness of different international burden divisions or policy instruments might also account for these results. In contrast, we report a survey experiment testing the sensitivity of CV responses to others' policy obligations, ceteris paribus. Cai et al. (2010) is the only CV study we have found to consider distributional concerns in this sense, whilst CV respondents' responsibility for the environmental problem, a different dimension of fairness, has been studied by Ajzen et al. (2000).

We note that effects of prospective cost shares would be open to interpretation. An important possibility has been raised within economics itself. A disposition to reason collectively, "team reasoning", has been posited by certain game theorists, to account for some of the observed phenomena of human cooperation (Sugden, 1993; Bacharach, 1997) and is a promising interpretation of data from relevant behavioural games (Bardsley et al., 2010). Under team reasoning, individuals ask themselves not "What should I do?" when making a decision, but "What should we do?", acting on considerations of which sets of actions are best for a group or society. This seems close to the vernacular concept of "doing one's bit", and the "we" perspective posited by Vatn (2009). It has been conceptualised in terms of plans with different parts for different members, with ideal characteristics of causal appropriateness to achieve the goal in question and equity between members (Bacharach, 2006). We hypothesise that many respondents are disposed to team reason when evaluating policy, and therefore that the distribution of costs over other members of society matters. Such a disposition would impact fundamentally on economic theory. To investigate this possibility, we incorporate postCV survey questions designed to probe motivation directly.

Our design and procedures are described in detail in the next two sections. We compare CV responses in two treatments. In the standard "no profile" treatment, no explicit information is given about others' obligations under the climate change mitigation policy. Without this it is natural for them to interpret the policy cost as a flat rate. In the "profile" treatment, respondents are told that richer sections of the population will pay more, and are shown an indicative schedule of incomes and payments. Other aspects of the scenario, including how much the sampled individuals would have to pay, are held equal across the treatments.

\section{A Survey Experiment on Contingent Valuation: Study Design}

The survey questions were organised in 4 parts. Part 1 asked for participants' demographic information. Part 2 contained questions about climate change and climate change policy. Part 3 introduced the CV scenario and elicited WTP. In Part 4 questions explored respondents' experience with and reasoning in answering the CV questions. It also presented four different payment distributions and asked participants which of these four they would vote for. Materials are available on request.

The questionnaires of the two treatments had identical parts 1, 2 and 4. The design of part 3 was driven by the objective to assess the effect of information about what others have to pay, "profile information", on contingent valuations. The aim was not primarily to assess the actual willingness-topay. Part 3 used both a binary (yes/no) and a maximum WTP format to ascertain the effect of the profile information. Our main hypothesis is that WTP is higher in the profile treatment, to be assessed 
using standard non-parametric tests: a chi-square test of independence for the binary data, and 2tailed Wilcoxon rank sum test for the maximum WTP data.

During the early days of contingent valuation studies, open questions of the type "What is the maximum you would be willing to pay for ?" were used to elicit the willingness-to-pay (Aizaki et al., 2015). Closed format questions were suggested by Bishop and Heberlein (1979) and endorsed by Arrow et al.'s (1993) report for the NOAA. This format asks respondents if they would be willing to pay a specific amount $Y$ for the outcome in question. The closed format is regarded as much easier for respondents to answer. It is perhaps most commonly framed as a referendum question in policy research, with participants asked if they would vote for the policy proposal or not. We did not adopt the referendum framing because of the inclusion of the open Maximum WTP question. This way we hold the framing constant across questions, but retain the simplicity of the closed format. Since closed questions have become the standard, we use this format first. To reduce potential anchoring effects, we separate the open format item with an additional question. This asks respondents to predict the percentage in favour of the policy.

The policy scenario was that, in the wake of the Paris agreement, a levy is proposed on taxpayers in order to reduce consumption and support the renewable energy sector. In the standard treatment, each participant was simply informed that she would have to pay $£ 1000$ per year. In the profile treatment, participants were informed that the contribution would depend on income. Those with incomes between $£ 14,000$ and $£ 46000$ would pay $£ 1000$, and those with higher incomes more. The information and questions for the CV questions are summarised in Table 1 below. In the profile treatment, the CV questions were followed up by asking whether their maximum WTP would require elsewhere to the schedule of payments, and if so to specify these. 


\begin{tabular}{|c|c|c|c|}
\hline & No profile & \multicolumn{2}{|l|}{ Profile } \\
\hline \multirow[t]{7}{*}{ Information } & \multirow[t]{7}{*}{$\begin{array}{l}\text { Following the Paris Agreement, } \\
\text { a levy is proposed on } \\
\text { taxpayers, in order to both } \\
\text { reduce consumption and } \\
\text { support the renewable energy } \\
\text { sector. You would have to pay } \\
\text { f1000 per year. }\end{array}$} & \multicolumn{2}{|c|}{$\begin{array}{l}\text { Following the Paris Agreement, a levy is } \\
\text { proposed on taxpayers, in order to both } \\
\text { reduce consumption and support the } \\
\text { renewable energy sector. People with } \\
\text { personal income between } £ 14,000 \text { and } \\
£ 46,000 \text { would have to pay } £ 1,000 \text { per year. } \\
\text { People with incomes above } £ 46,000 \text { would } \\
\text { have to pay a higher levy. The table below } \\
\text { gives examples of the levy for selected } \\
\text { incomes: }\end{array}$} \\
\hline & & Income per year & Levy per year \\
\hline & & $f 8,000$ & f0 \\
\hline & & $£ 30,000$ & $£ 1,000$ \\
\hline & & $£ 100,000$ & $£ 2,200$ \\
\hline & & $£ 500,000$ & $£ 11,000$ \\
\hline & & $f 1,000,000$ & $£ 22,000$ \\
\hline $\begin{array}{l}\text { CV section } \\
\text { Q1 } \\
\text { Q2 } \\
\text { Q3 }\end{array}$ & \multicolumn{3}{|c|}{$\begin{array}{l}\text { Would you be willing to pay this levy? Yes } \square \quad \text { No } \square \\
\text { What \% of the population do you think would be in favour? } \\
\text { What is the maximum levy you would be willing to pay? }\end{array}$} \\
\hline
\end{tabular}

\section{Table 1. Policy scenario by treatment and CV questions}

By selecting the sample according to income, we arranged that each participant would pay f1000 p.a. in both treatments, and by construction of the payment schedules, revenue was equalised across treatments. The need to equalise revenue across treatments meant that a truly progressive schedule, that is, with proportional payments increasing with income, could not be shown. The schedule is merely less regressive than the flat rate levy. $£ 1000$ p.a. is towards the high end of values reported in previous studies (Johnson and Nemet, 2010). Most studies, however, use samples including persons not in employment; we sample exclusively people in work. Renewable energy is also a relatively popular measure to specify as a destination for the revenue. We would therefore expect the typical willingness to pay to be higher than in a typical study. The payment schedules presented in part 4 were designed to raise the same overall totals. The calculations were based on the latest available UK income distribution figures (HMRC, 2016).

\section{Procedures}

The study was carried out at the University of Reading, UK, with 176 participants using pen and paper. Four sessions were run between June $20^{\text {th }}$ and July $4^{\text {th }} 2016$, two for each treatment, resulting in 91 completed questionnaires for the no profile treatment and 85 for the profile treatment.

Participants were recruited through a consumer testing agency based at the University of Reading, using filters on employment and income. Those contacted who confirmed that they were employed and had income ranging between $£ 14,000$ and $£ 46,000$ were invited to take part. Participants were aged between 20 and 65 with an average age of 42 and the gender split was 49 percent male and 51 percent female. 
Upon arrival participants were allocated to seats which were laid out in a way to provide privacy when filling in the questionnaire. An introduction to the study was given orally and in writing, and participants were given time to read and ask questions. The introduction set out basic scientific information about climate change, and gave some details about the research project and its funding. Questions were answered by the researchers in private. Participants were then asked to complete the questionnaire, consisting of parts 1-4 as described above. After all participants had finished, they were paid $£ 15$ each in cash for taking part.

\section{Results}

\subsection{CV questions}

\begin{tabular}{|c|c|c|c|}
\hline CV question & No profile & Profile & $\begin{array}{l}\text { Significance, } \\
95 \% \text { confidence interval }\end{array}$ \\
\hline $\begin{array}{l}\text { WTP Yes /No (question 1): } \\
\text { Count Yes/N } \\
\% \text { Yes }\end{array}$ & $\begin{array}{l}12 / 90 \\
13\end{array}$ & $\begin{array}{l}28 / 83 \\
34\end{array}$ & $\begin{array}{l}\text { Chisq }(1)=10.1 ; p<0.01 \text { (independence) } \\
4.3 \% \leq x \leq 36.4 \% \text { (difference in proportions) }\end{array}$ \\
\hline $\begin{array}{l}\text { Maximum WTP (question 3): } \\
\text { Mean (std) } \\
\mathrm{N}\end{array}$ & $\begin{array}{l}£ 400(f 456) \\
89\end{array}$ & $\begin{array}{l}f 517(£ 530) \\
81\end{array}$ & $\begin{array}{l}Z=1.05 ; p=1.00 \text { (Wilcoxon's rank sum) } \\
-f 73.00 \leq x \leq £ 307.86 \text { (difference in means) }\end{array}$ \\
\hline $\begin{array}{l}\text { Positive values: } \\
\text { Mean (std) }\end{array}$ & $\begin{array}{l}f 439(f 460) \\
81\end{array}$ & $\begin{array}{l}f 644(£ 517) \\
65\end{array}$ & $\begin{array}{l}Z=2.88 ; p=0.02 \text { (Wilcoxon's rank sum) } \\
£ 1.34 \leq x \leq £ 408.82 \text { (difference in means) }\end{array}$ \\
\hline $\begin{array}{l}\text { Zero values: } \\
\text { Count/N } \\
\% \text { Zero }\end{array}$ & $\begin{array}{l}8 / 89 \\
9\end{array}$ & $\begin{array}{l}16 / 81 \\
20\end{array}$ & $\begin{array}{l}\text { Chisq }(1)=4.1 ; p=0.18 \text { (independence) } \\
-2.7 \% \leq x \leq 23.6 \% \text { (difference in proportions) }\end{array}$ \\
\hline
\end{tabular}

Table 2. Results of CV survey questions by treatment

\section{Notes}

1. P-values and confidence intervals are Bonferroni-corrected: ' $p$ ' is multiplied by 4 and ' $\alpha$ ' by $1 / 4$.

2. Bootstrap confidence intervals were generated in STATA using the normal approximation method, drawing 10,000 bootstrap samples. The normality assumption was confirmed using 'probability normal' and 'quantile normal' diagnostic plots.

3. 3 observations were dropped as they reported a personal income below the payment threshold in the profile treatment.

4. 3 observations are missing from the maximum WTP data because of item non-response. 


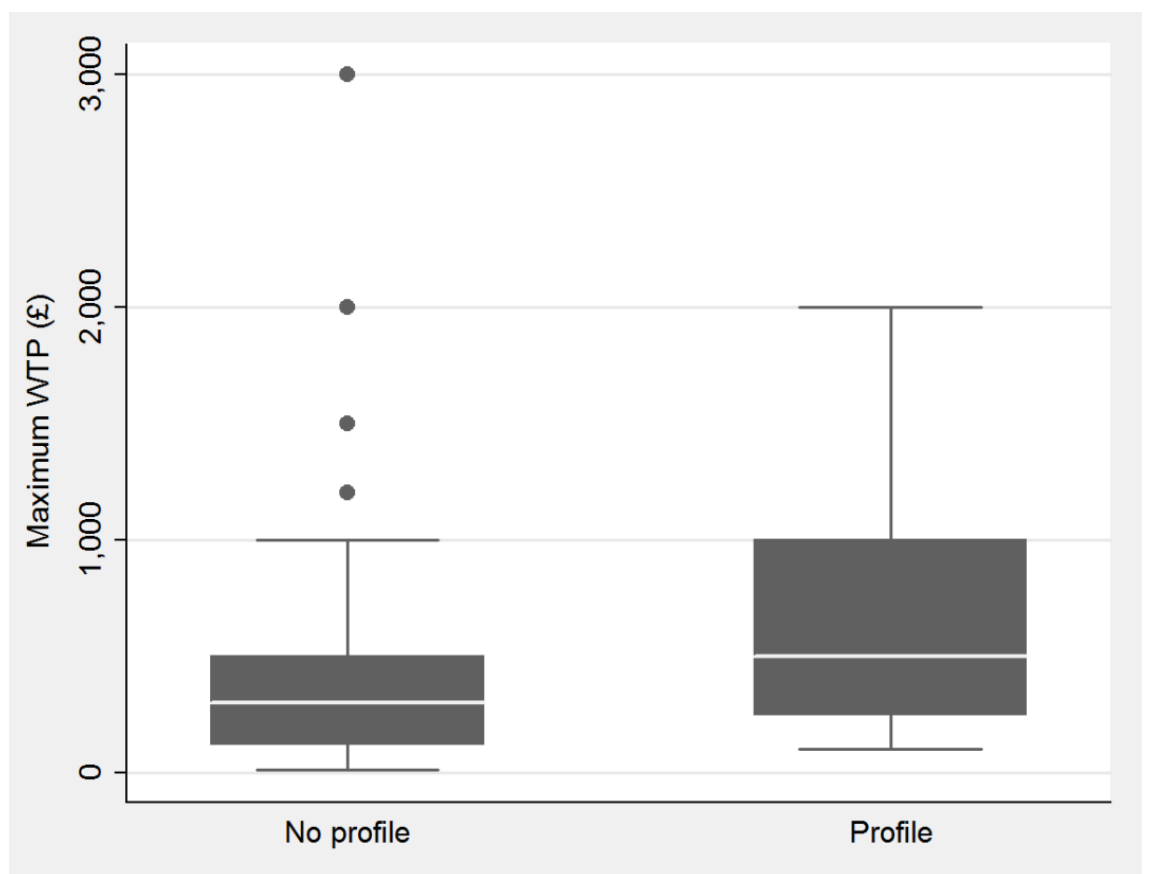

Figure 1. Distribution of positive willingness to pay values, by treatment Note

Boxes show the median and interquartile range. Bars extend to the most extreme value up to 1.5 times the interquartile range below the $25^{\text {th }}$ and above the $75^{\text {th }}$ percentiles.

\subsection{Post-experimental Survey}

We asked respondents directly how they had made their CV decision, including an option representing team reasoning and an option representing CV type reasoning. Other options were taken from pilot interviews when subjects attempted to explain their responses. $52 \%$ of subjects chose the team reasoning option, compared to $27 \%$ choosing the CV option (Figure 2, upper panel). We also probed motivation less directly, testing whether respondents wished to offload their costs onto the rich (Figure 2, lower panel). The question holds constant the income that would be harvested from the levy under four different schedules of contribution (Methods section) and asks respondents which schedule they would vote for. The proportion of the levy provided by richer sections of the population increases across schedules $A$ to $D$. By construction of the sample using income restrictions each respondent would have to pay the same amount, $f 1000$ per year, under schedules $A, B$ and $C$, but none would have to pay under D. Only $40 \%$ of respondents selected the schedule under which they would pay nothing. Two questions were included to provide insight into respondent's reasons for giving the responses they did. The question forms are shown in italics in Figure 2 below, with percentage responses.

\section{Analysis and Discussion}

We observe a clear effect of providing progressive profile information, compared to the standard formulation where no information is given about others' obligations. Acceptance of the policy, judged by survey question 1 , was significantly higher in the profile treatment, apparently making a difference of just over 20 percentage points (Table 2). Results for maximum WTP, question 2, were directionally consistent with the results for question 1 but not statistically significant. Since positive and zero values are often treated separately in CV studies, however, we also compare positive values obtaining a 
Q4 From the list below, please indicate which of the following statements most closely reflects how you decided whether or not you would be willing to pay the levy:

\begin{tabular}{|l|l|l|}
\cline { 3 - 3 } \multicolumn{2}{l|}{} & $\%$ \\
\hline & $\begin{array}{l}\text { To me, it does not matter how much other people contribute. } \\
\text { climate change. }\end{array}$ & 17 \\
\hline $\begin{array}{l}\text { I am not willing to pay anything because my contribution will } \\
\text { not make a difference. }\end{array}$ & $\mathbf{1 0}$ \\
\hline $\begin{array}{l}\text { I am not willing to pay anything because I do not believe that } \\
\text { climate change policies are effective. }\end{array}$ & $\mathbf{1 0}$ \\
\hline $\begin{array}{l}\text { I am willing to pay the amount that action on climate change } \\
\text { is worth to me. }\end{array}$ & $\mathbf{2 7}$ \\
\hline
\end{tabular}

Q5 In order to collect the same overall amount of the levy different amounts, varying with income, can be used. The table below gives details of four possible distributions of charges all raising the same overall amount of money. The amounts given are the levy that a person at these income levels would have to pay per year.

If you were asked to vote on the distributions, which one would you choose?

$A \square B \square C \square \quad D \square$

\begin{tabular}{|c|c|c|c|c|}
\hline & $\begin{array}{c}A \\
\text { everyone in } \\
\text { work pays }\end{array}$ & $\begin{array}{c}B \\
\text { those } \\
\text { earning } \\
\text { more than } \\
£ 12,000 \text { pay }\end{array}$ & $\begin{array}{c}C \\
\text { those } \\
\text { earning } \\
\text { more than } \\
\text { £14,400 pay }\end{array}$ & $\begin{array}{c}D \\
\text { those } \\
\text { earning } \\
\text { more than } \\
£ 70,000 \text { pay }\end{array}$ \\
\hline Income per year & \multicolumn{4}{|c|}{ Levy per year } \\
\hline$£ 8,000$ & $£ 1,000$ & $£ 0$ & $£ 0$ & fO \\
\hline$£ 13,000$ & $£ 1,000$ & $£ 400$ & fO & $£ 0$ \\
\hline$£ 20,000$ & $£ 1,000$ & $£ 1,000$ & $£ 1,000$ & $£ 0$ \\
\hline$£ 30,000$ & $£ 1,000$ & $£ 1,000$ & $£ 1,000$ & $f O$ \\
\hline$£ 70,000$ & $£ 1,000$ & $£ 1,540$ & $£ 1,000$ & fO \\
\hline$£ 100,000$ & $£ 1,000$ & $£ 2,200$ & $£ 2,700$ & $£ 16,500$ \\
\hline$£ 500,000$ & $£ 1,000$ & $£ 11,000$ & $£ 38,700$ & $£ 236,500$ \\
\hline$£ 1,000,000$ & $£ 1,000$ & $£ 22,000$ & $£ 83,700$ & $£ 511,500$ \\
\hline$\%(2 \%$ DNA $)$ & 8 & 18 & 32 & 40 \\
\hline$\%$ of Q1 WTP = Yes & 5 & 28 & 50 & 18 \\
\hline$\%$ of Q1 WTP = No & 9 & 15 & 26 & 47 \\
\hline
\end{tabular}

Figure 2. Percentage responses to direct (upper panel) and indirect (lower panel) questions probing motivation. 
significant test result. ${ }^{2}$ Comparison of zero values across treatments shows no significant difference in their incidence. ${ }^{3}$ Distribution plots for positive WTP values in each treatment are given in Figure 2, showing a $f 500$ difference between the upper quartiles, and inter-quartile ranges that are largely distinct.

The follow-up to the $\mathrm{CV}$ questions in the profile treatment confirmed that there is a relationship between valuation responses and parts to be played by others. For many subjects (55\%) wished to condition their maximum payments on an altered schedule for others' contributions. The general pattern of responses can be roughly characterised as wanting the richest to pay more. See Figure A1 (Appendix).

Two conclusions follow from the effects observed. Firstly, the power of the economic CBA approach to environmental policy analysis is undercut, since a different sum of estimated benefits will obtain for each way of distributing the costs of a policy. Secondly, the standard implementation of this exercise is likely to bias acceptance in a negative direction. This is because without explicit profile information, respondents are likely to interpret the policy as one that applies to everyone equally. For our policy this implies a "flat rate" charge, with everyone in work paying $f 1000$ regardless of their income. This would be to charge poorer persons more as a proportion of their incomes, a "regressive" policy. In contrast, realistic implementations of climate policies would have to counteract regressivity to ensure sufficient acceptance from the population.

As noted in our introduction, economists have theorised about matters such as fairness or equity, but this has not influenced working assumptions in applied work. We have chosen not to reach automatically for such terms because of the vagueness of the natural language, and the problematic nature of economic models of unselfishness. Conceptualised as interdependent utility, non-selfish motivation becomes a public good, subject to the false comparative static predictions of the pure theory of public goods. For a review see Bardsley (2000). Thinking of the result in terms of TR avoids this problem.

To probe TR empirically, we consider the results of two post-experimental survey, questions 4 and 5 , shown in Figure 2. Since it would be difficult to quantify team reasoning precisely using such questions, we first compared its apparent occurrence to that of CV type reasoning, and secondly probed respondents' willingness to offload costs onto others. Question 4 asked directly how respondents had made their decision for their answer to question 1 . We included items representing TR and CV reasoning, nested amongst three other responses which had occurred in pilot interviews. $52 \%$ of subjects selected the team reasoning response ("I am willing to do my part in the UK's contribution to tackle climate change") verses $27 \%$ for the CV response ("I am willing to pay the amount that action on climate change is worth to me"). So judging by self-report, team reasoning was more prevalent than $\mathrm{CV}$ reasoning.

Question 5 tests whether respondents wish simply to offload costs onto the rich. This would be expected if our treatment effect is driven by a desire to see the rich penalised. The question holds constant the income that would be harvested from the levy under four different schedules of

\footnotetext{
${ }^{2}$ A more involved treatment, common in CV exercises, is to treat "protest zeros" separately from "true zeros", with protests defined as objections to the policy rather than statements of no benefit (Strazzera et al., 2003). However, the distinction between protest and genuine zeroes is based on interpretations of survey responses, and often identifies few genuine zeroes for environmental policy. Given the global scope of climate change, it is hard to make sense of zeroes here other than as a form of protest response, including climate scepticism or pessimism concerning the feasibility of mitigation.

${ }^{3}$ Significance in Table 2 is not affected by use of Holm's or Hochberg's stepwise procedures, which are known to be less conservative than simple Bonferroni correction for multiple comparison.
} 
contribution, A-D, and asks respondents which schedule they would vote for. The proportion of the levy provided by richer sections of the population increases across A to D. By construction of the sample using income restrictions, each respondent would have to pay the same amount, $f 1000$ per year, under schedules $A, B$ and $C$, but none would have to pay under D. A respondent who has no inherent desire to be a part of the policy but who prefers that richer persons pay more would therefore choose schedule $D$, offloading the entire cost of the policy onto high earners. Although $D$ was the most frequent response, only $41 \%$ of respondents selected it, so $59 \%$ of respondents selected a schedule in which they themselves pay. Inspecting the data further, D is not the most popular choice amongst those who were willing to pay the levy, of whom only $18 \%$ chose it. On the other hand, it is also notable that the least popular schedule is the flat rate implementation, schedule A. Indeed, a negative association is evident between a schedule's regressivity and the frequency with which respondents chose it. Thus, implementations in which richer people pay more seem more popular, though respondents generally seem to favour a broad distribution of responsibility which includes themselves.

Further exploration of the data in Table 3 below offers some insight into the processes at work. We do not offer statistical tests for these comparisons as they were not pre-planned. Rather, we examine the pattern of responses to form plausible hypotheses. Firstly, our indicator of mode of reasoning does not seem to be associated with the inclusion of profile information, so it seems unlikely that the standard CV format is itself inducing individualism in respondents. The mode of reasoning indicator does appear to be associated with acceptance of the levy, however. A plausible mechanism behind our treatment effect, therefore, is that respondents are less likely to recognise the levy as "their part" in the UK's contribution to climate change mitigation if others' parts are not differentiated. This is consistent with their interpreting the policy in the no profile treatment as a flat rate charge.

\begin{tabular}{|l|l|l|l|l|}
\hline \multirow{2}{*}{$\begin{array}{l}\text { Reasoning } \\
\text { indicator (Q4) }\end{array}$} & \multicolumn{3}{|l|}{ Treatment } & WTP f1000 Levy? \\
\cline { 2 - 5 } & $\begin{array}{l}\text { No profile } \\
(\mathrm{N}=90)\end{array}$ & $\begin{array}{l}\text { Profile } \\
(\mathrm{N}=83)\end{array}$ & $\begin{array}{l}\text { Yes } \\
(\mathrm{N}=40)\end{array}$ & $\begin{array}{l}\text { No } \\
(\mathrm{N}=133)\end{array}$ \\
\hline Willing to do my part... & $46(51 \%)$ & $45(54 \%)$ & $35(87 \%)$ & $56(42 \%)$ \\
\hline $\begin{array}{l}\text { Willing to pay the } \\
\text { amount... worth to me }\end{array}$ & $23(25 \%)$ & $25(30 \%)$ & $8(20 \%)$ & $40(30 \%)$ \\
\hline
\end{tabular}

Table 3. Distribution of Reasoning Indicators by Treatment and Policy Acceptance

\section{Note}

Percentages in the third column sum to more than $100 \%$ because some respondents selected both answers for the reasoning indicator question.

Finally, we conducted a probit regression analysis (Aldrich and Nelson, 1984) of willingness to pay the levy against independent variables from the survey. Policy acceptance (question 1, Table 1) was regressed on the treatment variable, demographic variables and responses to the questions on climate change. Results are shown in the form of a coefficient plot (Jann, 2013) in the Appendix (Figure A2). Again, we do not offer the regression analysis in the mode of hypothesis testing but that of hypothesis formation, using confidence intervals as rough indicators of plausible hypotheses. The results strengthen confidence in our interpretation of the main result, as the coefficient on the treatment variable suggests a large effect after controlling for other factors. This implies that there is nothing in the data suggesting an alternative explanation, for example via any chance imbalance of 
attitudes across the sample. There also seems to be an association between policy acceptance and household, as opposed to personal, income, and, unsurprisingly, with perceptions that climate change is a threat to the respondent and their family.

\section{Conclusions}

We report a new problem for environmental CV in general, and its application to climate change policy in particular. Our CV survey experiment shows that respondents care not just about outcomes for themselves, but how those outcomes are produced in conjunction with others. Respondents' social motivation can be rationalised either as wanting the rich to pay more, or team reasoning. The latter seems to be at least partly responsible, judging by our post-experimental survey. Certainly our results cannot be attributed to a simple desire to penalise the rich, since most respondents favoured an implementation of a climate change policy which they themselves would contribute towards. The individualism of $\mathrm{CV}$ seems therefore to be undermined at both a practical and a fundamental level.

By showing sensitivity of reported CV responses to profile information, we are not thereby arguing for the incorporation of this information in future, in eliciting individuals' monetary values for policies. ${ }^{4}$ Such a revised approach would imply a different CBA for each way of implementing a policy, undermining the analytical power of CBA. Rather, we are drawing attention empirically to the fact that $\mathrm{CV}$ is theory-bound in a way that is problematic in the face of human sociality. Further, if CV research is really to be interpreted as research on public opinion regarding potential policies, as Naess (1989) argued, it is important to realise that it is likely to be a biased instrument for such research. For climate change mitigation policy, it is likely that the bias operates in a negative direction, under-estimating the likelihood of acceptance under a progressive implementation.

\section{References}

Adieh, R. (2011). Beyond individualism in law and economics. Boston University Law Review, 91, 4385.

Aizaki, H., Nakatani, T. and Sato, K. (2015). Stated Preference Methods Using R. CRC Press, Boca Raton, FL.

Ajzen, I., Rosenthal, L.H. and Brown, T.C. (2000). Effects of perceived fairness on willingness to pay. Journal of Applied Social Psychology, 30, 2439-2450.

Aldrich, J.H., and Nelson, F.D. (1984). Linear Probability, Logit, and Probit Models. Newbury Park, CA: Sage

Arrow, K., Solow, R., Portney, P.R., Leamer, E.E., Radner, R. and Shuman, H. (1993). Report of the NOAA panel on contingent valuation. Federal Register, 58, 4601-4614.

\footnotetext{
${ }^{4}$ As Spash (2008c) documents, economics practitioners' responses to anomalous CV results have generally been to devise ways for $\mathrm{CV}$ to avoid them by design or exclude them from analysis, rather than allowing that they require revisions to the underlying economic theory.
} 
Bacharach, M. (1999). Interactive team reasoning: A contribution to the theory of co-operation. Research in economics, 53, 117-147.

Bacharach, M. (2006). Beyond individual choice: teams and frames in game theory. Princeton University Press.

Bardsley, N. (2000). Interpersonal interaction and economic theory: The case of public goods. Annals of Public and Cooperative Economics, 71, 191-228.

Bardsley, N., Büchs, M. and Schnepf, S.V. (2017). Something from nothing: Estimating consumption rates using propensity scores, with application to emissions reduction policies. PLOS-ONE, 12, e0185538.

Bardsley, N., Mehta, J., Starmer, C., \& Sugden, R. (2010). Explaining focal points: cognitive hierarchy theory versus team reasoning. The Economic Journal, 120, 40-79.

Bergstrom, T. (1989). Love and spaghetti. The opportunity cost of virtue. Journal of Economic Perspectives, 8, 165-173.

Bishop, R.C., and Heberlein, T.A. (1979). Measuring values of extra-market goods: Are indirect measures biased? American Journal of Agricultural Economics, 61, 926-30.

Bockstael and Freeman (2005). Bockstael, N.E. and Freeman, A.M. (2005). Welfare theory and valuation. In Mäler, K.G. and Vincent, J.R. (Eds.) Handbook of Environmental Economics, Vol. 2, 517570 .

Boland, L.W. (1982). The Foundations of Economic Method. London: Allen and Unwin.

Borenstein, M., Hedges, L.V., Higgins, J.P.T. and Rothstein, H.R. (2009). Introduction to Meta-Analysis. Chichester: John Wiley and Sons.

Brand, C. and Boardman, B. (2008). Taming of the few: the unequal emissions of greenhouse gas emissions from personal travel in the UK. Energy Policy, 36, 224-238.

Cai, B., Cameron, T. A., and Gerdes, G. R. (2010). Distributional preferences and the incidence of costs and benefits in climate change policy. Environmental and Resource Economics, 46, 429-458.

Carson, R.T. and Hanemann, W.M. 2005. Contingent valuation. In Mäler, K.G. and Vincent, J.R. (Eds.) Handbook of Environmental Economics, Vol. 2, 822-920.

Gough, I. (2017). Heat, Greed and Human Need. Edward Elgar.

Hausman, J. (2012). Contingent valuation: from dubious to hopeless. Journal of Economic Perspectives, 26, 43-56. 
Hausman, J. and Diamond, P. (1994). Contingent valuation: is some number better than no number? Journal of Economic Perspectives, 8. 45-64.

HMRC (2016). National Statistics, Table 3.1a: Percentile points from 1 to 99 for total income before and after tax. Her Majesty's Revenue and Customs. Available at https://www.gov.uk/government/statistics/percentile-points-from-1-to-99-for-total-income-beforeand-after-tax; accessed March 2016.

Jann, B. (2013). Plotting regression coefficients and other estimates in Stata. University of Bern Social Sciences Working Papers Nr. 1.

Johnson, E. and Nemet, G.F. (2010). Willingness to pay for climate policy: a review of estimates. Working Paper \#2010-011. La Folette School of Public Affairs, University of Wisconsin-Madison.

Naess, A. (1989) Ecology, Community and Lifestyle. Outline of an Ecosophy. Trans. D. Rothenberg. Cambridge: CUP.

O'Neill, J. and Spash, C.L. (2000). Conceptions of value in environmental decision making. Environmental Values, 9, 521-536.

Oerlemans, L.A.G., Chan, K.Y., and Volschenk, J. (2016). Willingness to pay for green electricity: A review of the contingent valuation literature and its sources of error. Renewable and Sustainable Energy Reviews, 66, 875-885.

Operario, D., Adler, N.E. and Williams, D.R. (2004). Subjective social status: Reliability and predictive utility for global health. Psychology and Health, 19, 237-246.

Pollack, R. (1976). Interdependent preferences. American Economic Review, 66, 309-320.

Sen, A. (1973). On Economic Inequality. Oxford: Clarendon.

Spash, C.L. and Aslaksen, I. (2015). Re-establishing an ecological discourse in the policy debate over how to value ecosystems and biodiversity. Journal of Environmental Management, 159, 245-253.

Spash, C.L. (2008a). How much is that ecosystem in the window? The one with the bio-diverse trail. Environmental Values, 17, 259-284.

Spash, C.L. (2008b). Deliberative monetary valuation and the evidence for a new value theory. Land Economics, 84, 469-488.

Spash, C.L. (2008c). Contingent valuation design and data treatment: If you can't shoot the messenger, change the message. Environment and Planning C, 26, 43-53. 
Strazzera, E., Genius, M., Scarpa, R. and Hutchinson, G. (2003). The Effect of protest votes on the estimates of WTP for Use Values of Recreational Sites. Environmental and Resource Economics, 25, 461-476.

Sugden, R. (1993). Thinking as a team: Towards an explanation of nonselfish behavior. Social philosophy and policy, 10, 69-89.

Udehn, L. (2002). The changing face of methodological individualism. Annual Review of Sociology, 28, 479-507.

Vargas, A., Lo, A., Howes, M. and Rhode, N. (2017). The problem of inclusion in deliberative environmental valuation. Environmental Values, 26, 157-176.

Vatn, A. (2009). Cooperative behaviour and institutions. The Journal of Socio-Economics, 38, 188-196.

Venkatachalam, L. (2004). The contingent valuation method: a review. Environmental Impact Assessment Review, 24, 89-124.

World Bank (2012). Using contingent valuation in the design of payments for environmental services mechanisms: a review and assessment. World Bank Research Observer.

\section{Appendix}

For you to be willing to pay the maximum levy, would it be necessary to change what other people have to pay? Yes $\square \quad$ No $\square$

If yes, please indicate the changes in the levy that you would require:

\begin{tabular}{|l|l|}
\hline Income per year & Levy per year \\
\hline$£ 8,000$ & $£$ \\
\hline$£ 30,000$ & $£$ \\
\hline$£ 100,000$ & $£$ \\
\hline$£ 500,000$ & $£$ \\
\hline$£ 1,000,000$ & $£$ \\
\hline
\end{tabular}

Yes: $55 \%$ No: $45 \%$

\begin{tabular}{|l|l|l|}
\hline Income per year & Mean $(£)$ & Median $(£)$ \\
\hline$£ 8,000$ & 71 & 0 \\
\hline$£ 30,000$ & 560 & 500 \\
\hline$£ 100,000$ & 2619 & 2000 \\
\hline$£ 500,000$ & 15,606 & 12,500 \\
\hline$£ 1,000,000$ & 35,984 & 27,500 \\
\hline
\end{tabular}

Figure A1. Follow-up to the CV questions (left panel) and responses (right panel) to 1 s.f.

Note. To calculate the distribution of responses, two observations were dropped where respondents had given ranges, and cash amounts were calculated from four respondents who had specified percentages. 


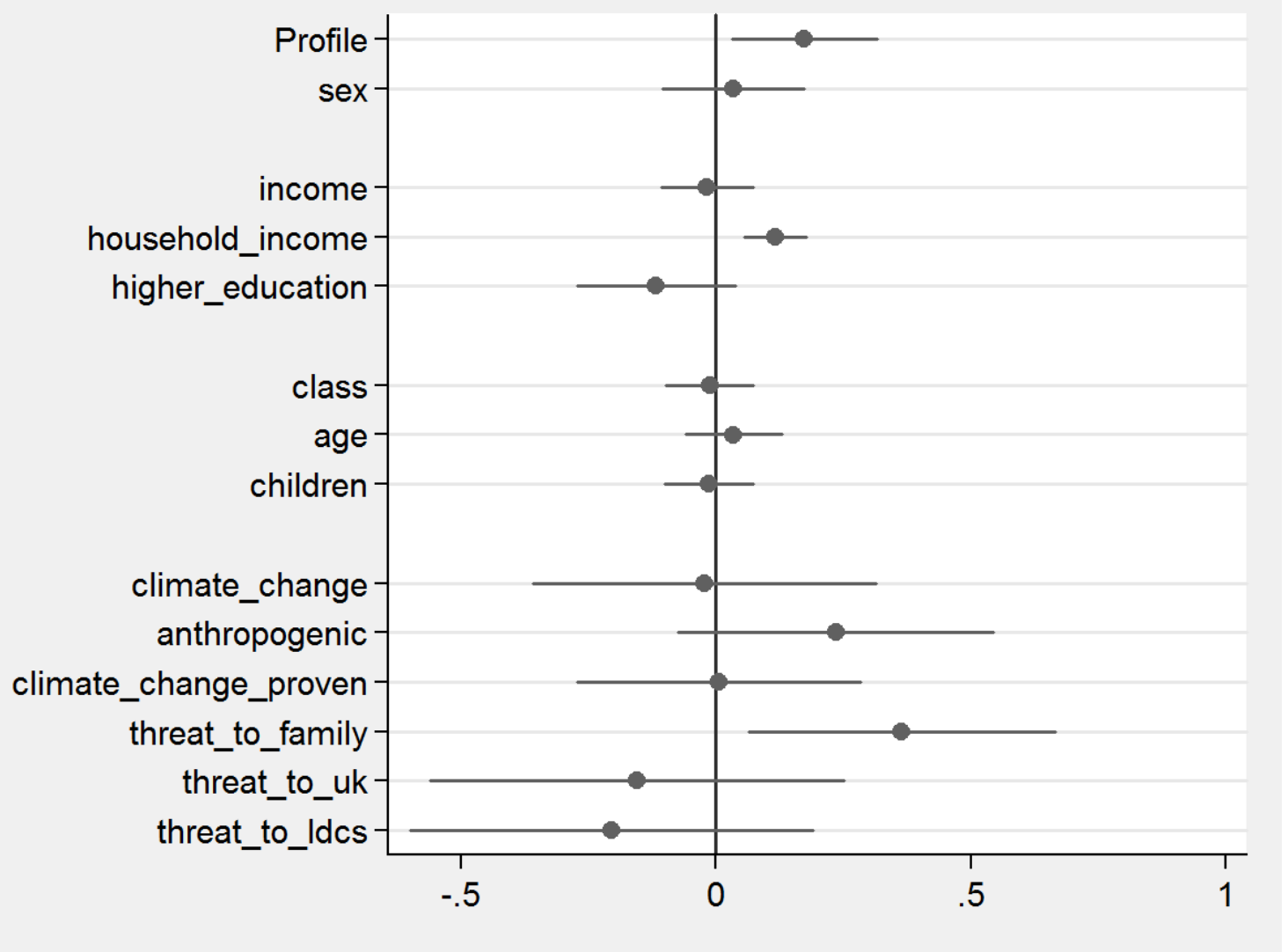

Figure A2. Coefficient plot of probit regression model of policy acceptance (CV question 1)

Notes.

1. The probit regression model is specified as $\operatorname{Pr}(Y=1 \mid X)=\Phi\left(X^{T} \beta\right)$, where $Y$ is the dependent variable, acceptance of the levy, and $X$ is a vector of covariates from the survey data plus a constant. The model was estimated using maximum likelihood in STATA. Marginal effects are shown for this model in Figure 3, defined as partial derivatives of $\Phi\left(X^{T} \beta\right)$ with respect to elements of $X$, calculated at the covariate values obtaining for each observation and averaged over the sample ("average marginal effects"). Coefficients are plotted as circles, and show marginal effects calculated at the mean values of the independent variables.

2. Independent variables are as follows. Profile = treatment (binary), sex = male or female (binary), income = personal annual income (banded scale), household_income = household annual income (banded scale), class = social class, measured using the subjective Macarthur Scale (Operario et al., 2004), age = respondent's age, children = number of children in the household. The remaining variables are Likertscale variables measuring degree of belief in climate change, whether climate change is believed to be anthropogenic, believed to be proved, seen as a threat to the respondent and their family, seen as a threat to the UK, and seen as a threat to less developed countries, respectively.

3. The non-binary variables were rescaled to have a mean of zero and standard deviation of 1 .

4. $\mathrm{N}=121$, because of item non-response. 